\title{
Active Disturbance Rejection Control of Valve-Controlled Cylinder Servo Systems Based on MATLAB-AMESim Cosimulation
}

\author{
Wenxiao Guo, ${ }^{1}$ Yanbin Zhao, ${ }^{2}$ Ruiqin Li ${ }^{1},{ }^{1}$ Haigang Ding $\mathbb{D}^{2},{ }^{2}$ and Jianwei Zhang ${ }^{3}$ \\ ${ }^{1}$ College of Mechatronics Engineering, North University of China, Taiyuan, Shanxi, China \\ ${ }^{2}$ School of Mechatronic Engineering, China University of Mining and Technology, Xuzhou, Jiangsu, China \\ ${ }^{3}$ Department of Informatics, University of Hamburg, Hamburg, Germany
}

Correspondence should be addressed to Ruiqin Li; liruiqin@nuc.edu.cn and Haigang Ding; haierdhg@126.com

Received 13 July 2020; Revised 27 July 2020; Accepted 31 August 2020; Published 11 September 2020

Academic Editor: Jing $\mathrm{Na}$

Copyright $(2020$ Wenxiao Guo et al. This is an open access article distributed under the Creative Commons Attribution License, which permits unrestricted use, distribution, and reproduction in any medium, provided the original work is properly cited.

The valve-controlled cylinder position servo system has the advantages of large output force and large power. As characteristics of nonlinearity and uncertainty exist in the hydraulic servo system, it is difficult for the traditional PID control to meet the requirements of high precision and control. The active disturbance rejection control (ADRC) considers the uncertainty of the system and external disturbances as the total disturbance. In this paper, the valve-controlled cylinder servo system is designed based on ADRC, its working principle is described, and its mathematical model and cosimulation model based on MATLAB-AMESim are established. In the case of constant load, variable load, and long pipeline, the comparative simulation of ADRC and PID is carried out. The simulation results show that the ADRC can effectively suppress the disturbance of the internal parameter changes and external load changes of the hydraulic system and has strong robustness and high control accuracy. This study provides a reference for the application of ADRC in electrohydraulic servo systems.

\section{Introduction}

The valve-controlled cylinder position servo system is a common hydraulic power execution system, with the advantages of large output force, large unit power volume ratio, and so on. It has been widely used in various fields. However, the electrohydraulic position servo control system is timevarying and nonlinear, such as nonlinearity of pressure flow and frictional force of the servo valve. It presents various features of time-varying parameters such as leakage coefficient, change of load, and change of damping ratio. Traditional PID control strategy is simple, but compared to some nonlinear, time-varying parameters of the system, it cannot achieve precise positioning control. In order to enhance the antijamming ability of electrohydraulic position servo control system while improving the precision control of the system, experts and scholars have researched a number of control strategies, including adaptive control, sliding mode control, and fuzzy control. Considering that the electrohydraulic servo system is nonlinear, Fang and Guan et al. [1-5] proposed an adaptive back-stepping sliding mode controller. The advantages of adaptive back-stepping control strategy and sliding mode controller strategy can be combined to strengthen the system's tracking performance. Zhang et al. [6] proposed a multimodel robust adaptive control theory. According to the range of parametric uncertainties, multiple identification models are designed and nonlinear robust items are added to the models to suppress the influence of uncertain nonlinearities and improve the robustness and the transient response performance of the system. $\mathrm{Na}$ et al. $[7,8]$ proposed a new control method without using the back-stepping scheme and any function approximators. They also propose an alternative and simple, yet efficient, estimation method to handle unknown dynamics and external disturbances for motion control of robotic systems. 
In 1999, Han [9-11] proposed the active disturbance rejection control (ADRC). In view of the fact that the parameter turning of the original nonlinear ADRC is complicated and not convenient for practical industrial application, Gao et al. [12-17] simplified the nonlinear part of the ADRC, proposed LADRC that is convenient to set parameters, and introduced the basic idea and principle of ADRC in detail. ADRC control strategy does not depend on the accurate mathematical model of controlled systems and considers the uncertainty of the system and external disturbance as the total disturbance. The extended state observer is used for observing internal parameter uncertainties and external disturbances, so that the disturbances of the system are suppressed effectively. For systems with larger amount of uncertainties both in dynamics and external disturbances, the precise control is realized with an ADRC controller. It has been successfully applied in industrial process, servo system control, automobile engine control, aerospace, and other fields and has a good prospect of engineering application. However, there are few reports about ADRC used in hydraulic servo systems $[18,19]$.

In this paper, an active disturbance rejection control strategy is developed to address those electrohydraulic position servo control systems with inherent nonlinear behaviors and modeling uncertainties. The simulation model of ADRC is established by using the MATLABAMESim cosimulation method in Simulink module library. The physical model of the valve-controlled cylinder position servo system was established on AMESim software. According to the simulation results, the effectiveness of the control method is verified and the influence of controller parameters on the control effect is analyzed.

\section{Mathematical Modeling}

The valve-controlled cylinder position servo system studied in this paper is shown in Figure 1. In this control system, the servo valve is the control component and the cylinder is the drive component. The cylinder displacement is detected using a displacement sensor and fed back to the ADRC controller to control the opening of the servo valve, so that the cylinder displacement is in the closed-loop control. The load (mass block) on the right is driven by the hydraulic cylinder. The main goal of this paper is to design the controller so that the hydraulic cylinder displacement controlled by the controller can track any given displacement as quickly as possible.

The flow equation of the servo valve is

$$
q_{L}=C_{d} \omega x_{v} \sqrt{\frac{P_{S}-P_{L} \operatorname{sgn}\left(x_{v}\right)}{\rho}} .
$$

Here, $C_{d}$ is the valve's port flow coefficient, $\omega$ is the servo valve's area gradient, $x_{v}$ is the servo valve's spool displacement, $P_{S}$ is the servo valve's inlet pressure, $P_{L}$ is the load pressure, and $\rho$ is the oil density.

$\operatorname{sgn}\left(x_{v}\right)$ is the symbolic function as follows:

$$
\operatorname{sgn}\left(x_{v}\right)= \begin{cases}1, & x_{v} \geq 0 \\ -1, & x_{v}<0\end{cases}
$$

Because the response speed of the servo amplifier is faster than that of the hydraulic system, the servo amplifier is treated as a proportional link to obtain the relationship between spool displacement $\left(x_{v}\right)$ and control input $(u)$, and

$$
x_{v}=K_{v} K_{s v} u,
$$

where $K_{v}$ is the gain of controller, $K_{s v}$ is the gain of the servo valve, and $u$ is the input signal of controller.

The flow continuity equation of the hydraulic cylinder is

$$
q_{L}=A_{P} \frac{\mathrm{d} x_{P}}{\mathrm{~d} t}+C_{t p} p_{L}+\frac{V_{t}}{4 \beta_{e}} \frac{\mathrm{d} p_{L}}{\mathrm{~d} t} .
$$

Here, $A_{P}$ is the effective area of the piston in the hydraulic cylinder, $x_{P}$ is the piston displacement, $C_{t p}$ is the total leakage coefficient of the hydraulic cylinder, $C_{t p}=C_{i p}+0.5 C_{e p}$, and $V_{t}$ is the total volume of the hydraulic cylinder cavity.

The force balance equation of the hydraulic cylinder and the load is

$$
A_{P} p_{L}=m_{t} \frac{\mathrm{d}^{2} x_{P}}{\mathrm{~d} t^{2}}+B_{p} \frac{\mathrm{d} x_{P}}{\mathrm{~d} t}+K x_{P}+F_{L}
$$

Here, $m_{t}$ is the total mass of the piston and the load, $B_{p}$ is the viscous damping coefficient of the piston and the load, $K$ is the spring stiffness, and $F_{L}$ is the accidental load force acting on the piston.

Take the state variables $x_{1}=x_{p}, x_{2}=\dot{x}_{p}$, and $x_{3}=\ddot{x}_{p}$, and they are displacement, velocity, and acceleration, respectively.

The state space expression of the servo system is

$$
\left\{\begin{array}{l}
\dot{x}_{1}=x_{2}, \\
\dot{x}_{2}=x_{3}, \\
\dot{x}_{3}=a_{0} x_{1}+a_{1} x_{2}+a_{2} x_{3}+b u+d, \\
y=x_{1},
\end{array}\right.
$$

where $a_{0}=-4 \beta_{e} C_{t p} / m_{t} v_{t}$,

$$
\begin{aligned}
a_{1} & =-\frac{K}{m_{t}}-\frac{4 \beta_{e}}{m_{t} V_{t}}\left(A_{p}^{2}-C_{t p} B_{p}\right), \\
a_{2} & =-\frac{B_{p}}{m_{t}}-\frac{4 \beta_{e} C_{t}}{V_{t}}, \\
b & =\frac{4 A_{p} \beta_{e} C_{d} \omega}{m_{t} V_{t} \sqrt{\rho}} \sqrt{P_{S}-P_{L} \operatorname{sgn}\left(x_{v}\right)}, \\
\mathrm{d}(t) & =-\frac{\dot{F}_{L}}{m_{t}}-\frac{4 \beta_{e} C_{t p} F_{L}}{m_{t} V_{t}},
\end{aligned}
$$

and $y$ is the output for system position. 


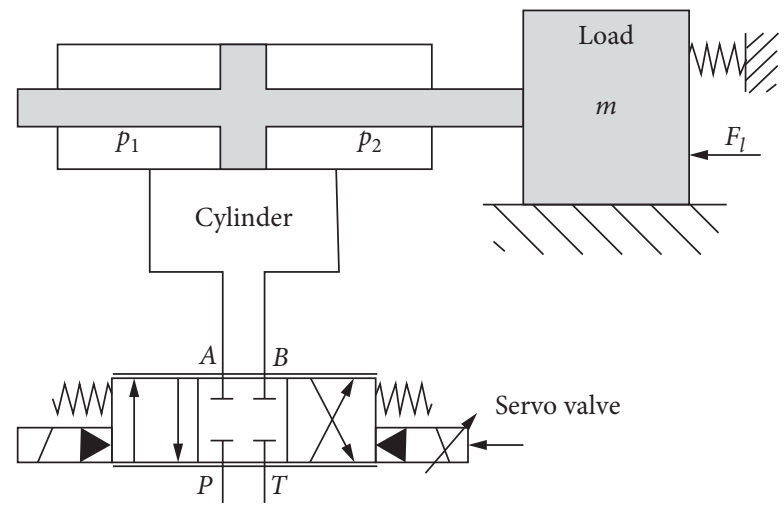

FIgURE 1: Model of valve-controlled cylinder position servo systems.

\section{Design of ADRC}

The core design of ADRC is to define an extended state, take the simple cascade integral form as the standard type, treat the parts of the system dynamic that are different from the standard type (including the uncertainty and disturbance of the system) as the total disturbance (including internal disturbance and external disturbance), and define the total disturbance into the extended state. Then, by means of the extended state observer, the total disturbance is estimated and eliminated in real time, so as to restore the controlled object free of disturbance, uncertainty, and nonlinearity to the standard integral series type and realize the control of the system. ADRC makes the control system design from complex to simple, from abstract to intuitive.

The linear ADRC consists of three parts: tracking differentiator, linear extended state observer, and linear state error feedback control law, as shown in Figure 2.

The design of ADRC does not need to rely on the specific mathematical model of a controlled object. It only needs to know the relative order of the system. For the design of LADRC based on generalized controlled object formula (6), the following steps are arranged.

3.1. Transition Process. In this article, "Arrange transition" and "Track-Differentiator" are combined to simplify the controller structure. As shown in Figure 3, the valve-controlled cylinder position servo system is a third-order system, so two tracking differentiators are used in series in the simulation process.

Arrange the transition process according to the set value $x_{0}$ as follows:

$$
\left\{\begin{array}{l}
\mathrm{fh}=\text { fhan }\left(x_{1}-x_{0}, x_{2}, r, h\right), \\
x_{1}=x_{1}+h x_{2}, \\
x_{2}=x_{2}+h \mathrm{fh} .
\end{array}\right.
$$

Define the fast-optimal control synthesis function of equation (9) as

$$
\mathrm{fh}=\mathrm{fhan}\left(x_{1}-x_{0}, x_{2}, r, h_{0}\right) .
$$

The realization of fh is shown in the following equation:

$$
\left\{\begin{array}{l}
d=r h_{0}, \\
d_{0}=h_{0} d, \\
y=x_{1}-x_{0}+h_{0} x_{2}, \\
a_{0}=\sqrt{d^{2}+8 r|y|}, \\
a= \begin{cases}x_{2}+\frac{\left(a_{0}+d\right)}{2} \operatorname{sign}(y), & |y|>d_{0}, \\
x_{2}+\frac{y}{h_{0}}, & |y| \leq d_{0},\end{cases} \\
\text { fhan }=- \begin{cases}r \operatorname{sign}(a), & |a|>d, \\
r \frac{a}{d}, & |a| \leq d .\end{cases}
\end{array}\right.
$$

Here, $h_{0}$ is the filter factor; $h$ is the simulation step length and is related to the sampling frequency of the system; $x_{0}$ is the expected displacement signal; and $r$ is the velocity factor, which determines the speed of tracking expected displacement signal.

3.2. Extended State Observer. The extended state observer of the system is established by tracking and estimating system state and disturbance with system output and input:

$$
\dot{x}_{3}=a_{0} x_{1}+a_{1} x_{2}+a_{2} x_{3}+b u+d .
$$




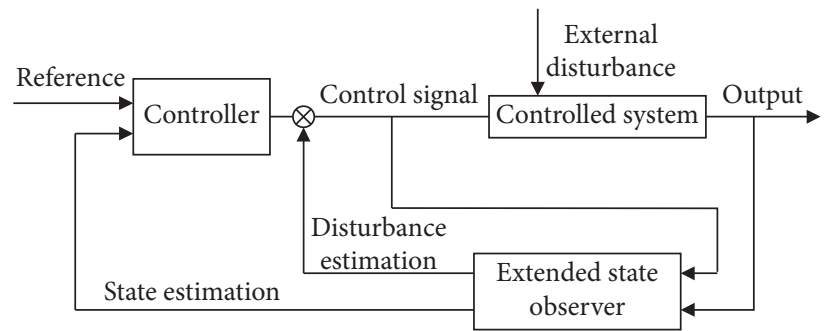

FIgURE 2: Structure of ADRC.

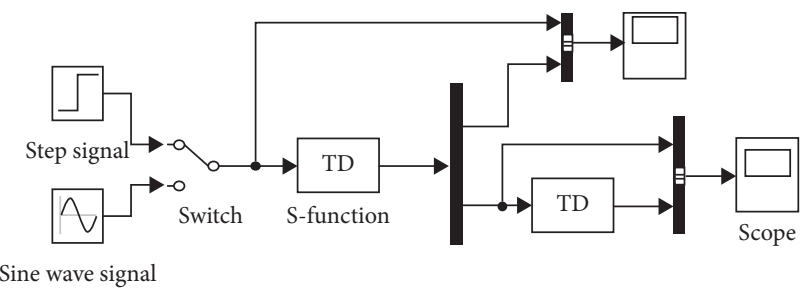

FIgURE 3: Schematic of the tracking differentiator.

Here, it is denoted that $\dot{x}_{3}=f\left(x_{1}, x_{2}, x_{3}, d\right)+b u$ to obtain the generalized controlled plant model:

$$
\left\{\begin{array}{l}
\dot{x}_{1}=x_{2} \\
\dot{x}_{2}=x_{3} \\
\dot{x}_{3}=f\left(x_{1}, x_{2}, x_{3}, d\right)+b u, \\
y=x_{1}
\end{array}\right.
$$

The real-time action of $f\left(x_{1}, x_{2}, x_{3}, d\right)$ on the system is expanded to a new state variable $x_{4}$, denoted as $x_{4}=f\left(x_{1}, x_{2}, x_{3}, d\right)$ and denoted as $\dot{x}_{4}=w(t)$. Then, the system (12) can be expanded into a new system as follows:

$$
\left\{\begin{array}{l}
\dot{x}_{1}=x_{2}, \\
\dot{x}_{2}=x_{3}, \\
\dot{x}_{3}=x_{4}+b u, \\
\dot{x}_{4}=w(t), \\
y=x_{1} .
\end{array}\right.
$$

A linear state observer is established for the extended system:

$$
\left\{\begin{array}{l}
e=z_{1}-y, \\
z_{1}=z_{1}+h\left(z_{2}-\beta_{01} e\right), \\
z_{2}=z_{2}+h\left(z_{3}-\beta_{02} e\right), \\
z_{3}=z_{3}+h\left(z_{4}-\beta_{03} e+b u\right), \\
z_{4}=z_{4}+h\left(-\beta_{04} e\right),
\end{array}\right.
$$

where $e$ is the output error. State observer (14) is called the extended state observer (ESO) of system (10), the variable $x_{4}$ is called the extended state, and the parameter of the ESO is

$$
\begin{aligned}
& \beta_{01}=\frac{1}{h} \\
& \beta_{02}=\frac{1}{3 h^{2}} \\
& \beta_{04}=\frac{5}{13^{3} h^{4}}, \\
& \beta_{03}=\frac{2}{8^{2} h^{3}} .
\end{aligned}
$$

This set of parameters is "inherited" for objects of the fourth order and below and is not limited by the estimated disturbance amplitude $\gamma$ [11].

3.3. Feedback Law of State Error. Linear state error feedback (LSEF) compensates the system disturbance through state error feedback. In this system, LSEF is designed as follows:

$$
\left\{\begin{array}{l}
e_{1}=x_{1}-z_{1}, \\
e_{2}=x_{2}-z_{2}, \\
e_{3}=x_{3}-z_{3}, \\
u_{0}=\alpha_{11} e_{1}+\alpha_{12} e_{2}+\alpha_{13} e_{3},
\end{array}\right.
$$

where $x_{i}(i=1,2,3)$ is the output value of the track differentiator, $z_{i}(i=1,2,3,4)$ is the output value of the ESO, $e_{i}(i=1,2,3)$ is the state error, $\alpha_{1 i}(i=1,2,3)$ is the gain coefficient of the controller, and $u_{0}$ is the linear error feedback control quantity. Considering the disturbance error of the system, the final output of linear ADRC is obtained by compensating $u_{0}$ :

$$
u=u_{0}-\frac{z_{4}(t)}{b_{0}} .
$$


3.4. Parameter Tuning. The ADRC controller has many parameters to be tuned. According to the functions of the tracking differentiator, the ESO, and the feedback control law, the parameters can be set independently according to the "separation principle":

(1) The parameter $r$ mainly affects the performance of the tracking differentiator. When $r$ becomes larger, the response of the system becomes faster and the tracking accuracy becomes higher, but the overshoot of the system becomes larger as well. When $r$ is small, the tracking speed of the system will become very slow, even unable to track the reference input signal.

(2) The increase of $\beta_{01}$ and $\beta_{02}$ in a certain range has no great influence on the control effect of the system, but when $\beta_{01}$ is large, the system is prone to divergent oscillation and when $\beta_{01}$ is small, the tracking effect of the system will become worse, so $\beta_{01}=1 / h$ is generally adopted. Larger $\beta_{03}$ will produce highfrequency noise signals, resulting in poor system control, but smaller $\beta_{03}$ will increase the number of oscillations and increase the amplitude, so generally $\beta_{03}=2 / 8^{2} h^{3}$; when $\beta_{04}$ decreases, the tracking speed of the system slows down, the transition process tends to be stable, but it is easy to cause a large phase lag, so $\beta_{04}=5 / 13^{3} h^{4}$.

(3) $b_{0}$ is the only variable related to the controlled system in the whole controller. The choice of different $b_{0}$ values is equivalent to the change of the total disturbance value in different ranges; that is, the compensation component will also produce corresponding changes. The gain $\alpha_{11}$ of the controller affect the corresponding rapidity of the system, but overshoot occurs when $\alpha_{11}$ is too large. An appropriate controller gain $\alpha_{12}$ will reduce overshoot.

\section{Cosimulation Modeling}

Because the electrohydraulic position servo control systems have inherent nonlinear behaviors and modeling uncertainties, it is difficult to establish an accurate mathematical model, so the cosimulation platform using MATLAB and AMESim is applied in this work. The mechanical and hydraulic parts are built in AMESim and the control part is modeled by MATLAB-Simulink. By using AMESim's interface technology to Simulink and combining two excellent professional simulation tools, AMESim's outstanding fluid mechanical simulation performance can be brought into play and Simulink's powerful numerical processing capability can be utilized to achieve more perfect complementary effects.

The cosimulation principle of the valve-controlled cylinder servo system in ADRC based on MATLAB-AMESim platform is shown in Figure 4. The concrete realization process of cosimulation between AMESim and Simulink is as follows: First, create an interface through the interface menu in the AMESim to connect Simulink. Next, complete the submodel mode and parameter mode setting. Finally, run the hydraulic system model to generate S-function for
Simulink. A cosimulation model built on MATLABAMESim platform is shown in Figure 5, nad main parameters of the system are listed in Table 1 .

ADRC parameters are set as follows: $r=0.25, h=0.011$, and $T=0.011$.

Observer parameters are

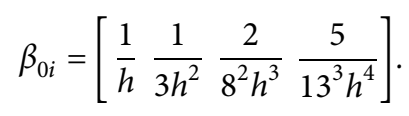

Controller parameters are

$$
\begin{aligned}
b_{0} & =50, \\
\alpha_{1 i} & =\left[\begin{array}{lll}
400 & 0.062 & 0.1
\end{array}\right] .
\end{aligned}
$$

PID control is the most common and effective control method in engineering and its controller is designed as follows:

$$
u=K_{p} e+K_{i} \int_{0}^{t} e \mathrm{~d} t+K_{d} \frac{\mathrm{d} e}{\mathrm{~d} t},
$$

where $K_{p}$ is the proportional gain, $K_{i}$ is the integral gain, $K_{d}$ is the differential gain, and $e$ is the error. Those parameters are tuned to the best after many tests. In this paper, ADRC and PID are compared and analyzed.

\section{Simulation Results and Analysis}

In order to analyze the dynamic performances of the system in ADRC, the following three simulation scenarios are designed in this section: (1) dynamic responses under constant load; (2) dynamic responses under variable load; (3) dynamic responses under long pipeline. Comparative analyses of the control characteristics of ADRC and PID are made.

5.1. Dynamic Responses under Constant Load. When the load force is constant, step responses of the system in ADRC and PID are shown in Figure 6, where reference displacement of the hydraulic cylinder is $200 \mathrm{~mm}$. Under this condition, the parameters of PID are set as follows: $K_{p}=200, K_{i}=105$, and $K_{d}=2.5$. Figure 6(a) shows that, under the ADRC and PID, the maximum rise time is $0.5 \mathrm{~s}$ and $1 \mathrm{~s}$, respectively; the maximum adjustment time is $1.2 \mathrm{~s}$ and $5 \mathrm{~s}$, respectively; and the maximum overshoot quantity is $1 \%$ and $9.5 \%$, respectively. Figure 6(b) shows that, compared to PID, the spool displacement under the ADRC changes smoothly during the process of opening, there is no impact, and the maximum opening is about $80 \%$ larger.

Figure 7 indicates sinusoidal response under ADRC and PID. It shows that the system in ADRC can accurately track the reference signal with smaller phase lag. In the initial stage, the displacement of the spool in ADRC is large, so that the hydraulic cylinder can quickly refer to the signal. Then, the spool displacement is basically the same as the PID control. In the commutation phase, the overshoot of the hydraulic cylinder under ADRC control is smaller than under PID control. 


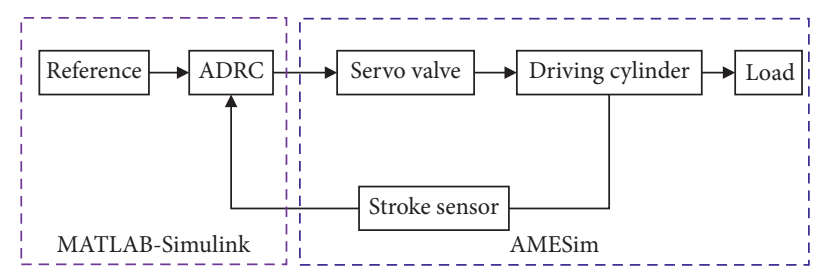

FIGURE 4: Schematic diagram of cosimulation principle.

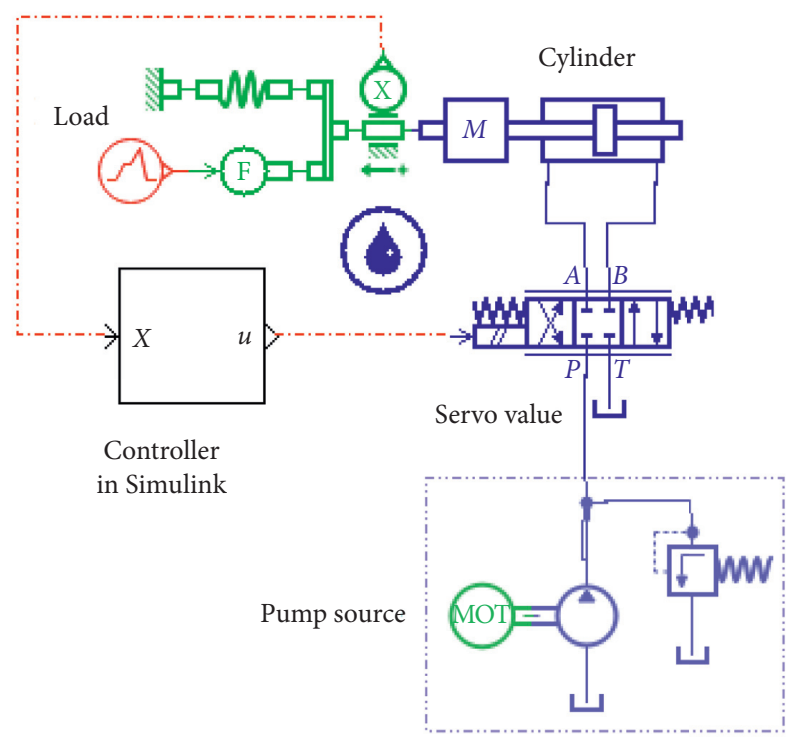

(a)

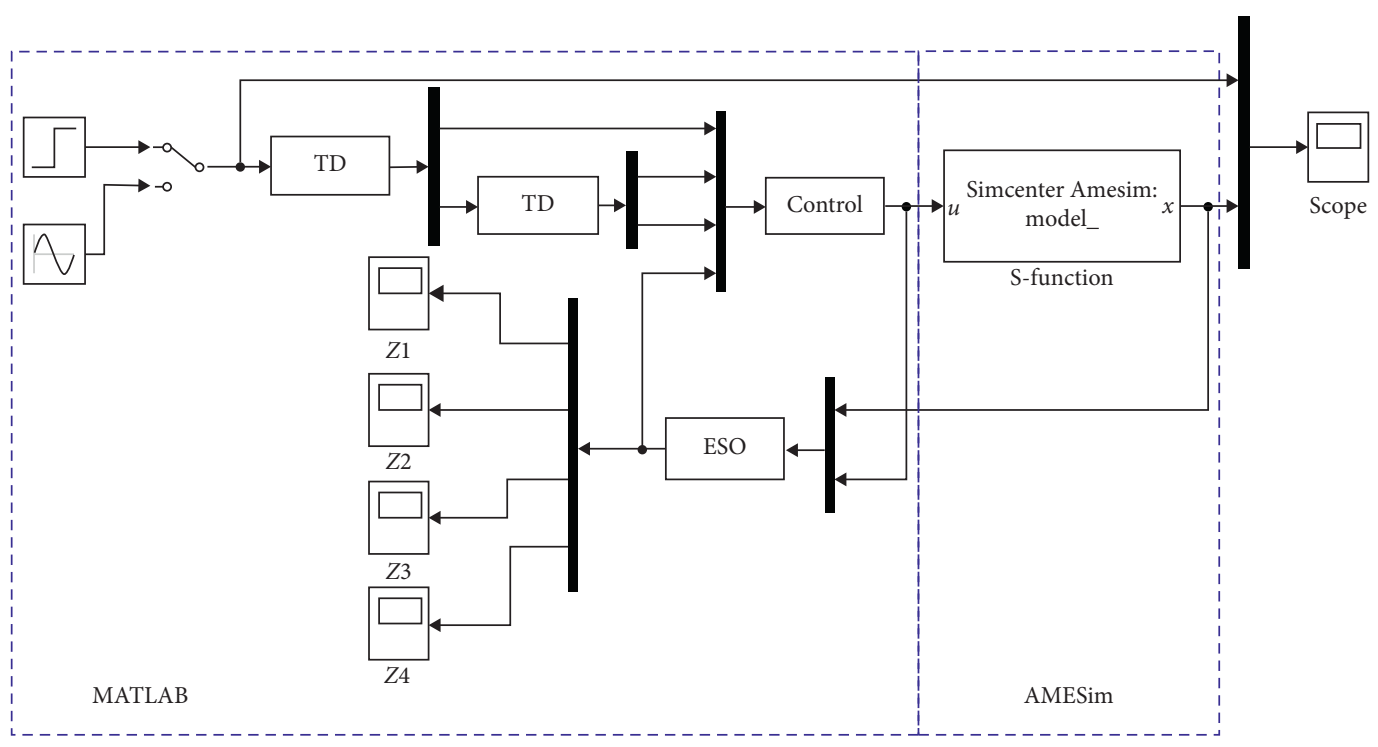

(b)

FIGURE 5: Cosimulation model. (a) Hydraulic system model in AMESim. (b) ADRC model in MATLAB.

The step response and sinusoidal response show that ADRC has more advantages than PID and the system in ADRC has fast dynamic response and high control accuracy.
5.2. Dynamic Responses under Variable Load. In practice, the load usually changes, so it is necessary to investigate the dynamic characteristics of the control system under variable load. In this part, the load force is variable in the simulation 
TABLE 1: Main parameters of the system.

\begin{tabular}{lc}
\hline Parameters & Value \\
\hline Cylinder diameter & $45 / 63 \mathrm{~mm}$ \\
Load mass & $100 \mathrm{~kg}$ \\
Motor speed & $1500 \mathrm{r} / \mathrm{min}$ \\
Pump delivery & $100 \mathrm{~mL} / \mathrm{r}$ \\
Relief pressure & $350 \mathrm{bar}$ \\
Load spring rate & $10000 \mathrm{~N} / \mathrm{m}$ \\
\hline
\end{tabular}

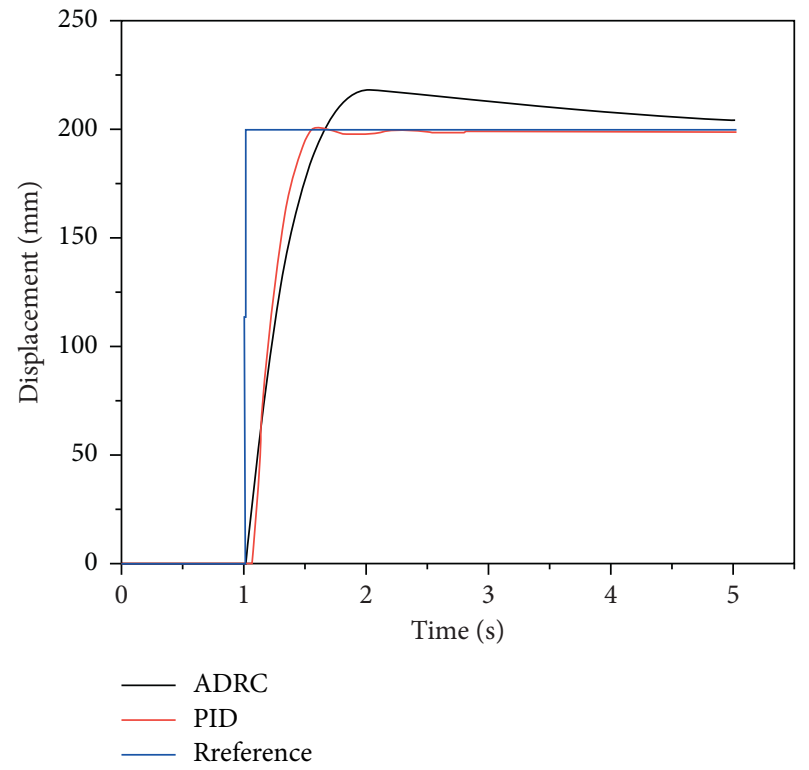

(a)

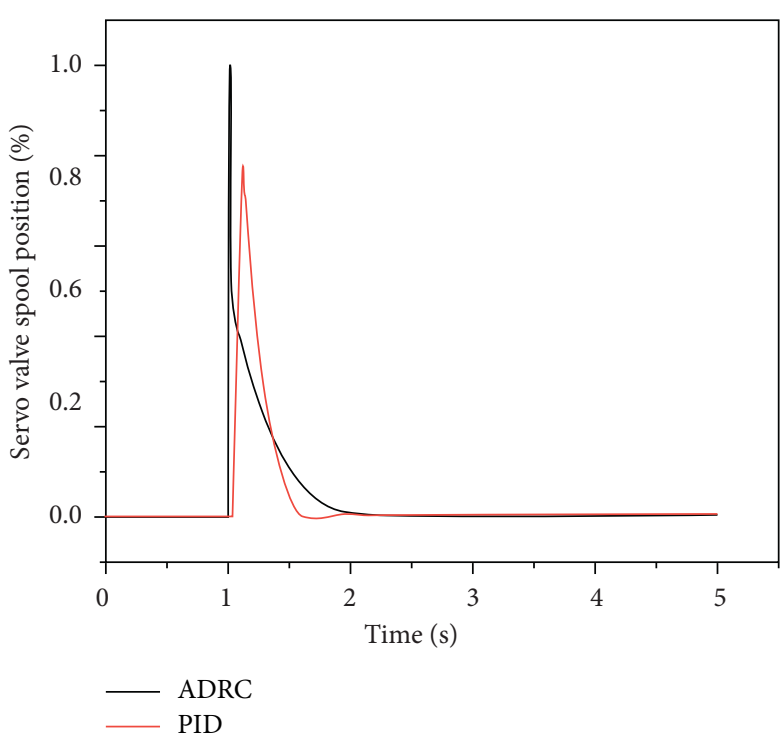

(b)

FIGURE 6: Step responses in ADRC and PID under constant load. (a) Cylinder displacement response. (b) Spool position response.

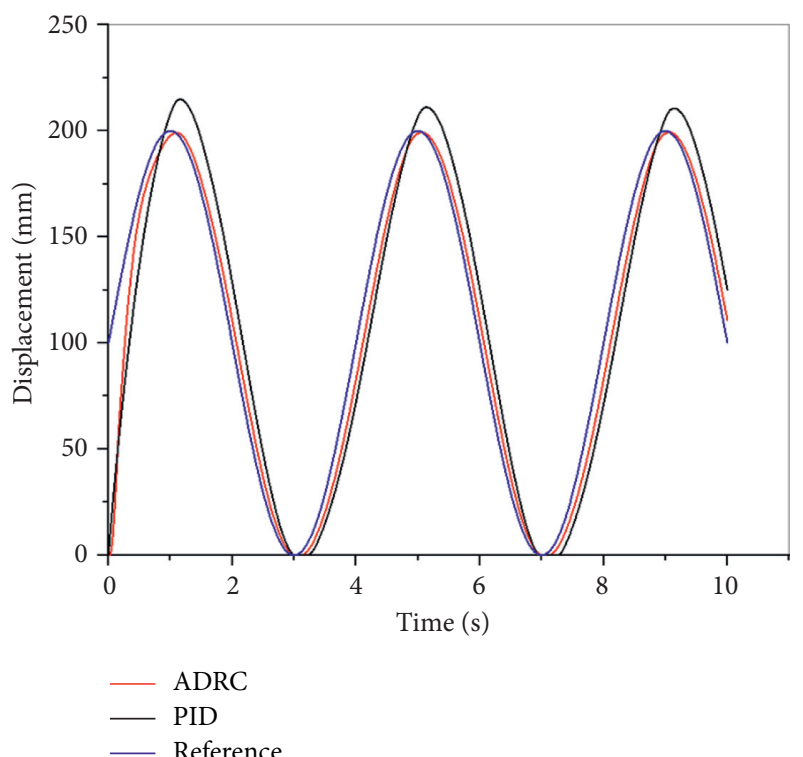

(a)

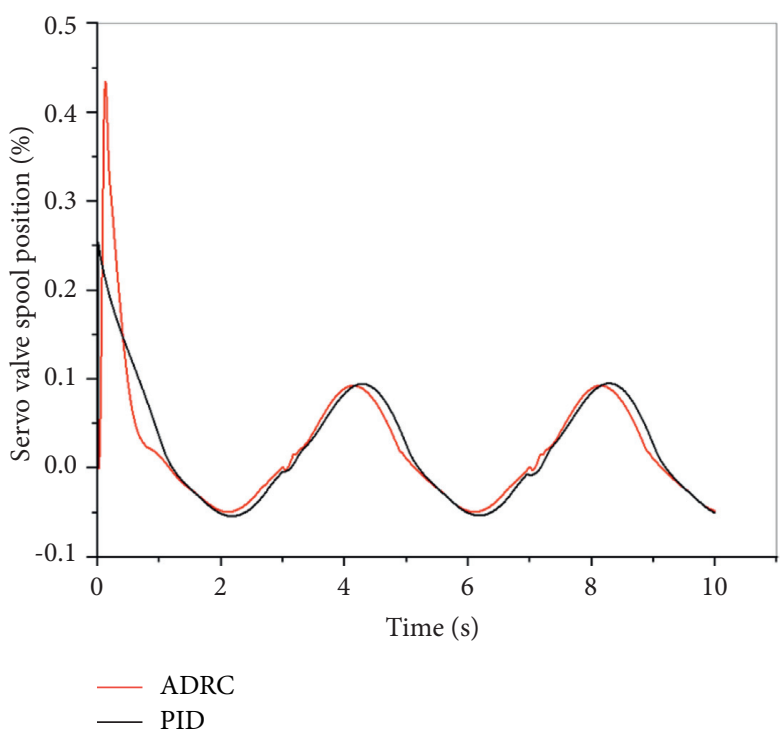

(b)

FIgURE 7: Sinusoidal responses in ADRC and PID under constant load. (a) Cylinder displacement response. (b) Spool position response. 

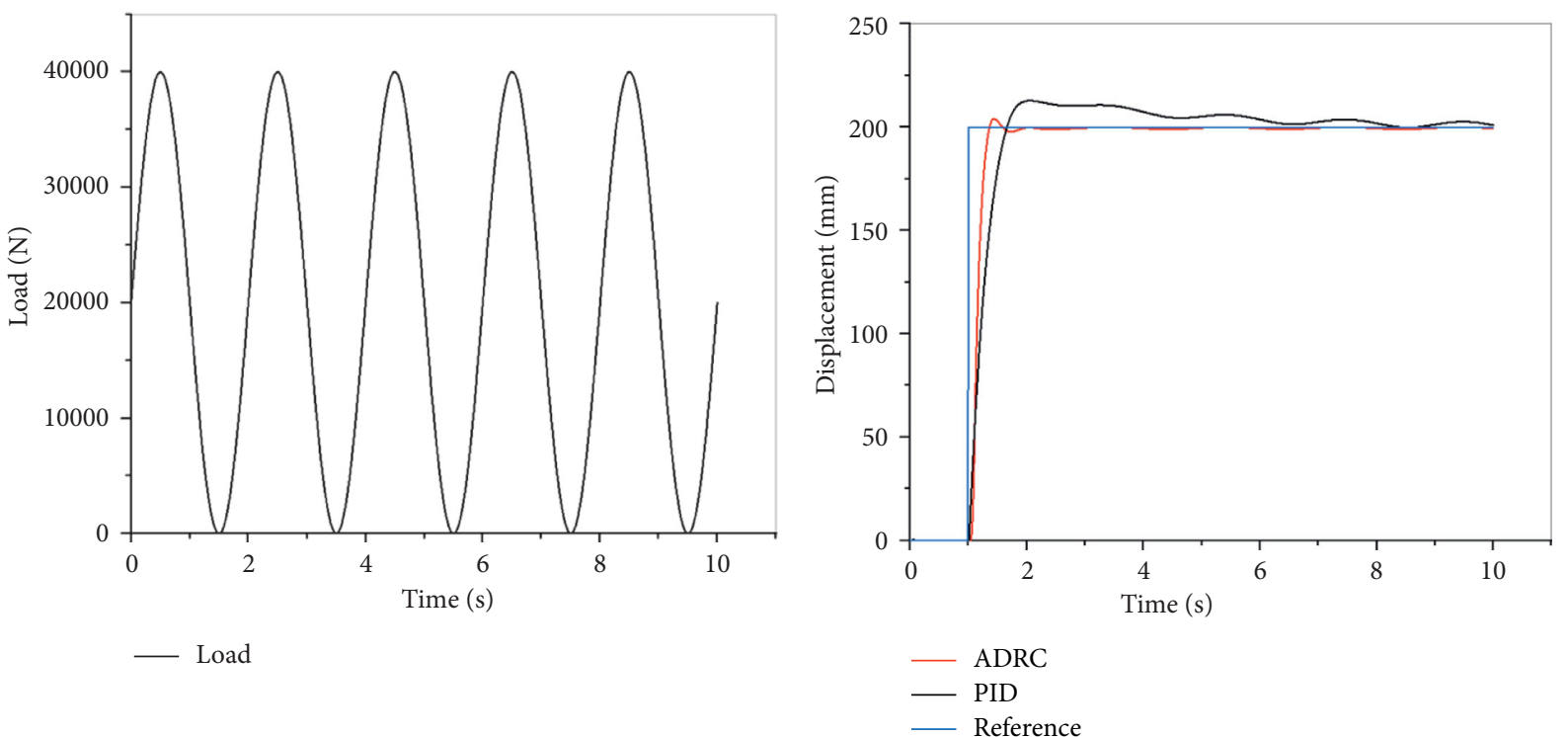

(a)

(b)

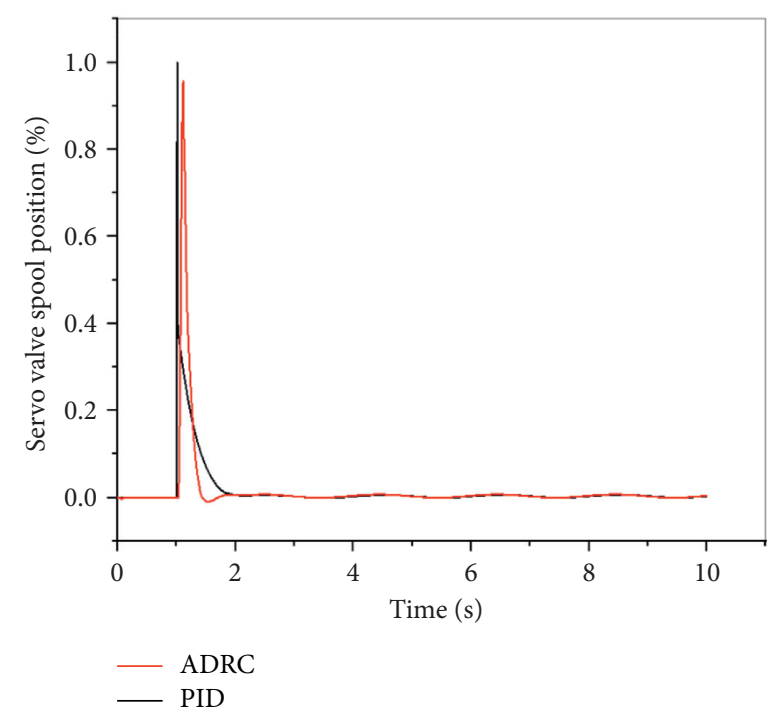

(c)

FIGURE 8: Step responses in ADRC and PID under variable load. (a) Sinusoidal load. (b) Cylinder displacement response. (c) Spool position response.

process. Under this condition, the parameters of PID are set as follows: $K_{p}=200, K_{i}=85$, and $K_{d}=2$.

Figure 8 shows that the actual displacement of the hydraulic cylinder controlled in ADRC and PID will be affected to different degrees in the process of load change. However, the ADRC controller considers the external disturbance as total disturbance and the disturbance is estimated and eliminated by the extended state observer in real time, so as to realize accurate control. Therefore, the system in ADRC can respond faster and can track the reference displacement. In addition, in the early stage of response in ADRC, the opening of the servo valve is very large to move the hydraulic cylinder to the set position quickly. The cylinder displacement controlled by PID not only takes a long time to reach the set value but also fluctuates greatly by the variable force, resulting in poor stability.

5.3. Dynamic Responses under Long Pipeline. The hydraulic pipeline is one of the indispensable components of the hydraulic system and plays the role of connecting the component and the transmission medium. The characteristics of the pipeline have a great influence on the dynamic and static characteristics of the hydraulic system. When the pipeline is short, the pipeline effect can be ignored, but when the pipeline is long, the pipeline effect will cause the response to lag and the control accuracy will reduce. This section mainly discusses the dynamic characteristics of systems with 


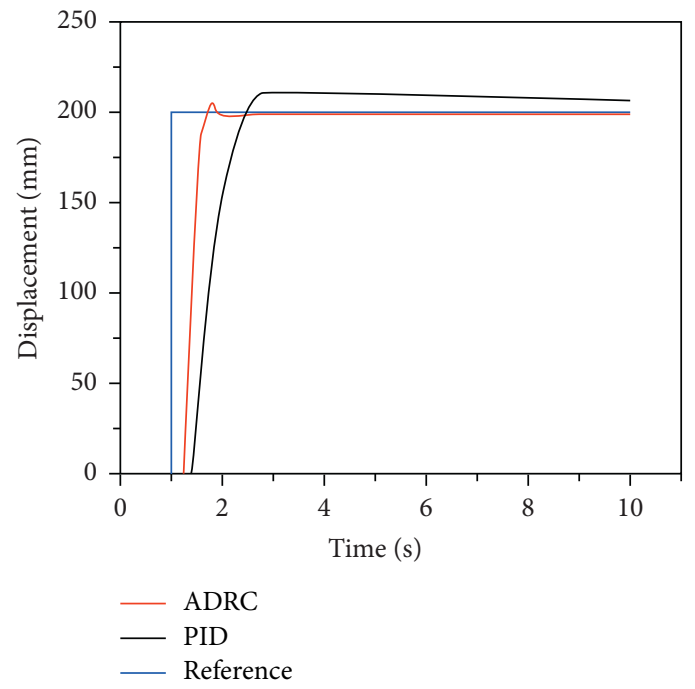

(a)

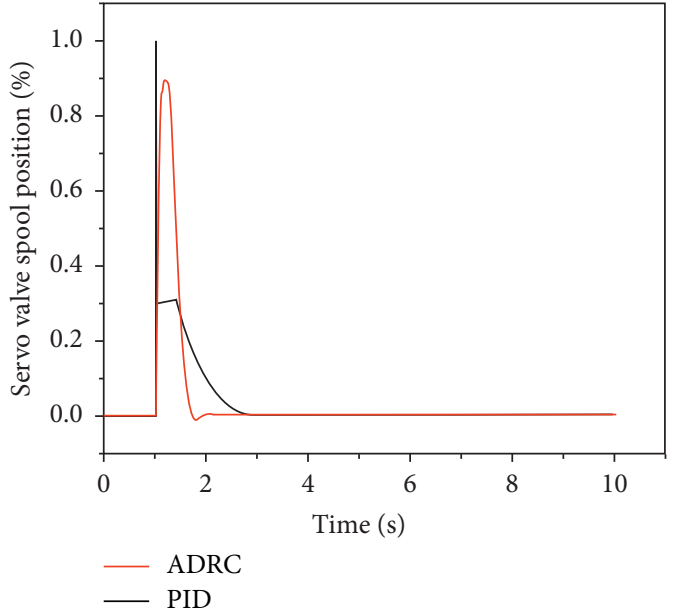

(b)

Figure 9: Step responses of the hydraulic system with long pipelines. (a) Cylinder displacement response. (b) Spool position response.

long pipelines. In the simulation, the pipeline length is set to $50 \mathrm{~m}$ and diameter is set to $25 \mathrm{~mm}$. Under this condition, the parameters of PID are set as follows: $K_{p}=105, K_{i}=20$, and $K_{d}=0.1$.

The simulation results shown in Figure 9 indicate that there is a certain delay in the step response of the long pipeline hydraulic systems, but the delay by ADRC is short. The hydraulic cylinder in PID control has a long adjustment time and a large overshoot, while that in ADRC can reach the set position quickly, and there is almost no overshoot. It can be seen that ADRC has obvious advantages in the hydraulic system with long pipelines.

\section{Conclusion}

(1) A cosimulation model of the valve-controlled cylinder based on MATLAB-AMESim platform is more accurate than the mathematical model and is closer to the real system.

(2) The structure and basic principles of active disturbance rejection control are introduced; the active disturbance rejection controller is designed, and the rule of parameter setting is clarified.

(3) The comparative simulation with ADRC and PID is carried out in cases of constant load, variable load, and long pipeline. The simulation results show that the ADRC can effectively suppress the disturbance of the internal parameter changes and external load changes of the hydraulic system, has strong robustness and control accuracy, and has potential in electrohydraulic systems for highperformance control.

\section{Data Availability}

The data used to support the findings of this study are included within the article.

\section{Conflicts of Interest}

The authors declare that there are no conflicts of interest regarding the publication of this article.

\section{Acknowledgments}

This work was supported by the Fundamental Research Funds for Central Universities (2019XKQYMS37), the Key Research and Development Program of Shanxi Province (International Cooperation) (201903D421051 and 201803D421028), and the Youth Fund Project of Shanxi Province (201901D211210).

\section{References}

[1] Y. M. Fang, Y. C. Han, L. L. Zhao, and Q. Li, “Adaptive control for electro-hydraulic servo system with uncertain coefficients in control input," Control Theory and Application, vol. 26, no. 2, pp. 156-160, 2009.

[2] Y. M. Fang, Z. X. Jiao, W. B. Wang, and P. Z. Shao, "Adaptive back-stepping sliding mode control for rolling mill hydraulic servo position system," Electric Machines and Control, vol. 15, no. 10, pp. 95-100, 2011.

[3] S. Y. Ruan, G. J. Li, and X. H. Jiao, "Adaptive control for VSCHVDC systems based on back-stepping method," Electric Power Systems Research, vol. 77, no. 5, pp. 559-569, 2011.

[4] C. Guan and S. Pan, "Adaptive sliding mode control of electro-hydraulic system with nonlinear unknown parameters," Control Engineering Practice, vol. 16, no. 11, pp. 1275-1284, 2008. 
[5] C. Guan and S. A. Zhu, "Back-stepping based multiple cascade adaptive sliding mode control of an electro-hydraulic servo system," Acta Instrumentation, vol. 26, no. 6, pp. 569-573, 2005.

[6] Y. Z. Zhang, Q. li, W. C. Zhang, and Y. Y. Yang, "Survey of multi-model adaptive control theory and its applications," Chinese Journal of Engineering, vol. 429, no. 2, pp. 135-143, 2020.

[7] J. Na, Y. Li, Y. Huang, G. Gao, and Q. Chen, "Output feedback control of uncertain hydraulic servo systems," IEEE Transactions on Industrial Electronics, vol. 67, no. 1, pp. 490-500, 2020.

[8] J. Na, B. Jing, Y. Huang, G. Gao, and C. Zhang, "Unknown system dynamics estimator for motion control of nonlinear robotic systems," IEEE Transactions on Industrial Electronics, vol. 67, no. 5, pp. 3850-3859, 2020.

[9] J. Q. Han, "Active disturbance rejection controller and its applications," Control and Decision, vol. 13, no. 1, pp. 19-23, 1998.

[10] J. Q. Han, "From PID technology to active disturbance rejection control technology," Control Engineering of China, vol. 9, no. 3, pp. 13-18, 2002.

[11] J. Q. Han, "Parameters of the extended state observer and fibonacci sequence," Control Engineering of China, vol. 15, pp. 1-3, 2008.

[12] S. Chen, W. Y. Bai, Y. Hu, Y. Huang, and Z. Q. Gao, "On the conceptualization of total disturbance and its profound implications," Science China Information Sciences, vol. 63, no. 2, pp. 221-225, 2020.

[13] Z. Q. Gao, "On the foundation of active disturbance rejection control," Control Theory and Application, vol. 30, no. 12, 2013.

[14] Z. Q. Gao, "Scaling and bandwidth parameterization-based controller tuning," in Proceedings of 2003 American Control Conference, pp. 4989-4996, Denver, CO, USA, June 2003.

[15] Z. Q. Chen, J. J. Liu, and M. W. Sun, "Overview of a novel control method: active disturbance rejection control technology and its practical applications," CAAI Transactions on Intelligent Systems, vol. 13, no. 6, pp. 866-877, 2018.

[16] Y. Huang, W. C. Xue, and C. Z. Zhao, "Active disturbance rejection control: methodology and theoretical analysis," Journal of Systems Science and Mathematical Sciences, vol. 31, no. 9, pp. 1111-1129, 2011.

[17] Z. Gao, "Engineering cybernetics: 60 years in the making," Control Theory and Technology, vol. 12, no. 2, pp. 97-109, 2014.

[18] B. W. Gao, J. P. Shao, and X. D. Yang, "A compound control strategy combining velocity compensation with ADRC of electro-hydraulic position servo control system," ISA Transactions, vol. 53, no. 3, pp. 1910-1918, 2014.

[19] J. T. Miao, X. L. Yao, J. X. Zhang, and S. W. Yang, "Application of ADRC in hydraulic AGC system," in Proceedings of the $33 \mathrm{rd}$ Chinese Control Conference, Nanjing, China, July 2014. 